\title{
Spatial inequality of innovation development in Russia
}

\author{
YURI V. PREOBRAZHENSKIY ${ }^{1}$, ANNA A. FIRSOVA ${ }^{2}$, DMITRIY A. MUZHENSKIY ${ }^{3}$ \\ ${ }^{1,3}$ Faculty of geography, ${ }^{2}$ Faculty of economy \\ Saratov State University \\ 83, Astrakhanskaya Str., Saratov, 410012 \\ RUSSIA
}

\begin{abstract}
The article provides the spatial aspects of the effectiveness improving of the national innovation system. The role of regional innovative spillovers in the development of innovative activity is determined. The question is raised about the prerequisites for the knowledge flow between the last two. The internal morphology of the innovative space is analyzed to identify the territorial features of knowledge spillovers, based on the frame and center-peripheral approaches. The problems of the unevenness of innovative activity in Russian regions are considered, zones of the center, semi-periphery and periphery of the innovative space of the country are identified. The lack of innovative cores, the large distances between existing ones do not allow to form a full-fledged innovative framework of the country, creating conditions for the diffusion of innovations and the flow of knowledge. In conclusion, directions are proposed for reducing the spatial polarization of innovation and increasing the potential for the impact of innovative spillover effects on the sustainability of regional innovation systems.
\end{abstract}

Key-Words: - knowledge spillover, innovation activity, center, periphery, innovative space, diffusion of innovation.

Received: January 10, 2020. Revised: May 10, 2020. Accepted: May 22, 2020. Published: June 16, 2020.

\section{Introduction}

Sustainable national economic development in its essence should be characterized by the leading role of scientific, technological progress and the intellectualization of the main production factors. The intensity and effectiveness of innovative activity largely determines the level of the national economy development. Many years of experience in developed countries confirms the success of the state innovative policy implementation, which creates an internal potential for effective growth in the economy and ensures sustainable innovative development in the long term.

Ensuring the country's scientific, technological leadership and competitiveness in the world market depends on level of development of the national innovation system at the macro level and of the regional innovation systems in the regions. For its part, the effectiveness of the national innovation system determines the speed of dissemination of knowledge between its actors and knowledge spillovers.

In this context, the methodology for the study of innovative spillover effects in regional economies and the determination of spatial innovation development trends is an urgent scientific task. This task is to study the effectiveness of innovative activities and determine the long-term consequences of the state structural policy of financing innovation.

In addition, it is used to define measures to improve the efficiency of regional innovation systems. All the above determine the relevance and timeliness of this study.

The object of research is the national innovative space, which can be described as the spatial measurement of the national innovation system. It is the space, in which innovations originate (generate) and spread (diffuse).

The subject of the study is the possibility of applying the center-peripheral and wire-frame approaches to the study of relations in the structure of the national innovative space.

The authors tested the hypothesis of the most significant manifestation of innovative spillover effects between relatively closely located innovation centers, based on the Russian regions empirical data.

The purpose of the article is to study the internal morphology of the innovative space to identify the territorial features of knowledge spillovers, using the example of the Russian Federation.

The goal is specified in a number of research tasks: 
1) to determine the role of the knowledge spillovers for the development of the national innovative sphere;

2) to consider the problems of uneven innovation in the Russian regions;

3) to propose measures to reduce spatial differentiation and increase the potential of spillover effects in regional innovation systems.

\section{Literature Review}

Researchers were involved with the subject of the knowledge dissemination and innovation (which can be regarded as a certain type of knowledge) for decades. Currently, most authors adhere to the position, that the diffusion of innovations can occur through the transfer of technology (i.e., the intentional transfer to a specific person or company) and through the spillover effects of knowledge or innovation. Moreover, if the diffusion of innovations proper was initially considered as a spatial process (the fundamental author research of this term by T. Högerstrand focused on this [1]), then the spillover effects of knowledge dissemination began to be considered only from the perspective of the spatial approach in the last quarter century. And prior to that, the territorial limitations of the spillover effects appearance were ignored. Only in the 1990s researchers began to study the geographical extent of knowledge dissemination [2]; the first use of the term "local knowledge spillovers" appeared in 1995 [3;4].

The analysis of innovative spillover effects and their manifestations in national innovation systems is actively explored by authors. The degree of the spatial spillover effect between scientific research and high-tech innovations, produced in the regions, is studied in the classical researches of foreign scientists. For example, Feldman and Florida mean by spillover the result of the spread and transfer of technology and innovation between actors of the innovation system [5]. The idea of an innovation space, where national and regional innovation systems exist, has been actualized by Sørensen and Cornett [6].

Geographic location and economies of agglomeration are vital for knowledge generation, dissemination, spillover, and application [7].

R. Capello identifies the different modes of performing phases of the innovation process and identifies different territorial patterns of innovation and highlights the context conditions (internal and external to the region) that accompany each innovation pattern [8].
J. Stejskal, P. Hajek and O. Hudec provides an assessment of the economic and social impact of resulting knowledge spillovers of Central and Eastern European countries and identifies key distinguishing factors of the regional innovation systems dynamics [9].

The concept of economic polarization was introduced to the economic literature by J. Esteban [10]. The idea of polycentric development using to ensure regionally balanced development in EU. EU documents underlines that new spatial strategy should reduction of the disparities between the center and periphery and to prevent a further concentration of spatial development in just few single globally outstanding dynamic integration zone. European spatial development programs analyse the directions of greater opportunities for training and mobility incentives for researchers from disadvantaged EU regions with diverse research centres region for co-operating and polycentric and balanced spatial development in the EU [11].

P. Lukaze studies the economic polarization in countries of the EU at NUTS-2 in the years 20072012 and found that even the economic crisis of 2008-2013 did not play any role in the raising of the economic polarization in EU countries [12].

C. Zou, X. Ou and J. Tan proposed the instruments and standard for rationally dividing the economic polarization level and judging the alert level of China provinces' regional economic polarization [13].

M. Tal and V. Maarten examine the contributions associated with increasing inequality and urban-development processes to neighbourhood and identifies the relative roles of these processes in generating socio-economic change in the Tel Aviv metropolitan area in Israel [14].

M. Alonso attributed spatial uneven development in sub-Sahara Africa thorough inequalities in comparative advantage within the neoclassical framework of free and competitive markets and structural hegemony of primate cities [15].

In modern Russian literature, various manifestations of knowledge spillovers in the innovation sphere are actively investigated $[16,17]$. The universal issues of the spillover effects manifestation of modern Russia, as applied to the conditions of innovation diffusion, are studied in the details in the researches of O. G. Golichenko [18], in which the general innovation system characteristics, the state of innovation activity in the business environment, the production of innovative products and the influence of innovative processes are disclosed competitiveness, factors hindering the development of the enterprise innovative potential. 
Particular attention is paid to the role of science and the production of knowledge in the innovative process development, the higher education sector of the innovation system, and the implementation of the state's innovation policy foundations. The theoretical foundations of the "innovative spillover" concept are analyzed by V.I. Cherenkov et al. [19].

P. A. Minakir and A. N. Demyanenko explore the problems of spatial economics and centerperipheral systems, explore the measurement and maximization of economic systemic effects, the ability to self-generate economic growth [20]. The study of diffusion of innovation and the development of new information, communication and innovation technologies is carried out by V.L. Baburin and S.P. Zemtsov [21], V.I. Blanutsa [22].

It should be noted that Russian authors are limited to the theoretical approaches analysis to research, while there is a very low number of research papers on the quantitative assessment of innovative spillover effects.

The spatial aspect of functioning of national system of innovation widely discussed in the previous researches, but the results showing simple compression between some regions. The goal of this text is to be more specific about the condition of national innovation space and its structure. It is necessary to determine the spatial configuration of regions (or parts of them) in the national innovation space, which will allow them to increase the innovation potential of each other and receive positive effects, such as spillover effect. The low population and economic density in Russia is a challenge for research, which creates unusual conditions and requires consideration of these specific features.

Thus, the methodological issues of the quantitative assessment of spillover effects in the innovative development of the region are no fully developed, which determines the scientific novelty of this research.

\section{Innovative space: the problem of unevenness}

The structure of the innovative space of some region or country is represented by the core of innovation activity, the axes between them (linear elements) and a relatively rarefied zone, in which innovation activity is weakly or completely absent.

The characteristics of the diffusion innovation are determined by the properties of the innovative space. In this research the latter is considered as one of the spaces, whose properties determine various types of human activity.
The morphology of the innovative space and the links between the components can be considered from the perspective of the center-periphery model. The innovative space is not closed: it is affected by the economic space (the ratio of supply and demand, concentration of financial resources and access conditions to them, etc.), the information space (in which, in fact, innovative knowledge arises that can be commercialized and framed as a specific innovation).

Between such spaces, in addition to direct (controlled) influence, processes of unintentional influence occur, including, due to the properties of systems, enclosed in such spaces (innovative, economic, etc.). Such externalities that affect the development and change of the innovative space are commonly called spillover effects.

Innovative spillover effects are side effects of economic, innovative and accompanying processes of dissemination and transfer of technology and innovation.

The spillover effect of knowledge is a phenomenon that occurs when the information collected and used to implement a specific project (or activity) ultimately creates new opportunities for applying this knowledge in other areas. The spillover serves as a catalyst for the development of new ideas and methods of their application [23].

Spillovers can be external to the innovative space in the case, when they are derived from processes, occurring in the economic and information spaces. On the other hand, spillover effects are also observed in the most innovative space.

Internal spillovers are manifested in the interaction of participants within one organization, the exchange of information, knowledge, technologies and human resources between divisions of the same organization (internal organizational spiller) or industry (intersectoral spillover).

Nowadays, one of the main problems of socioeconomic development is the increasing scale of spatial socio-economic heterogeneity, differentiation and increasing inequality in the territory development at all levels. So, the great differentiation by gross regional product reflects the depth of regional inequality in the Russian Federation.

Innovative space has a common "spatial" property - heterogeneity. It is the heterogeneity of the innovative space that allows describing the differences in the speed and number of generated innovations, and also determines the different speed of their diffusion. By resolving the task of describing the innovative space, determining 
qualitative and quantitative indicators in different areas, it is possible to predict the development and to manage the innovation sector of the region, country, and the world.

In this research the innovative space is understood as a set of conditions that determine innovative activity, as well as territorial manifestations of this activity. Accordingly, the innovative space of the center, semi-periphery and periphery has different potential for innovative development and mutual influence. The properties of the innovative space determine one or another intensity of innovation reproduction and the speed of their distribution (Fig. 1).

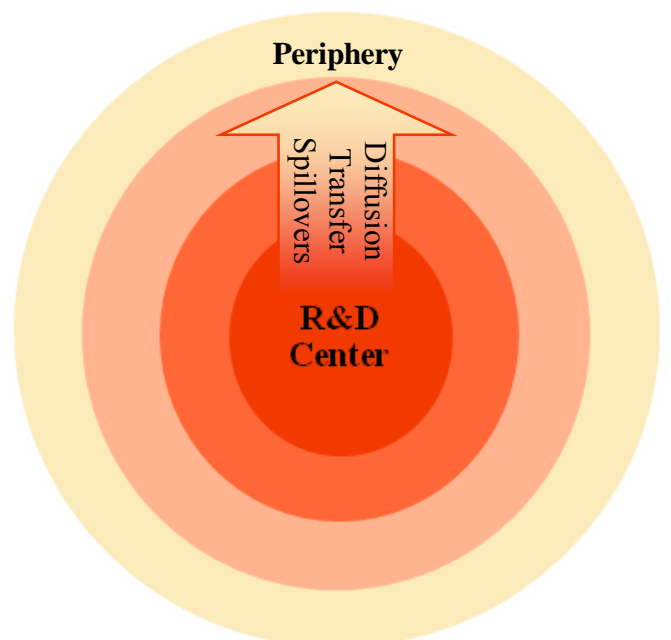

Fig. 1. The intensity of knowledge

dissemination from the Center to the Periphery during the innovation process

In this research the study of the innovative space is considered from the perspective of two methodological approaches: a framework approach and an approach, based on the Center-Peripheral model.

An innovative space is structured by the following components. The accumulation of innovation will be the core; first of all, these are points of innovation generation. Axes are linear structures between the cores, which are usually confined to infrastructure or to the coasts. The most active flow of knowledge and innovations goes along them.

It is possible to consider frames of different structures (monocentric - with one clearly defined center, bicentric - with two centers, polycentric with several centers; different configurations of the frame axes are also possible). It is obvious that the more polycentric the innovative space, the more cores and axes the innovation framework contains, the more it (the innovative space) is stable and productive and has the greater impact on the economic space.

The approach, associated with the application of the Center-Periphery model, allows describing the links between the most developed, dense zones of the innovative space (center) and the most rarefied zones (periphery).

The spatial approach, based on the centerperiphery model, is also associated with systemic properties. In particular, certain processes between the center zones and the periphery give stability to the system, each zone performs certain functions.

According to the Center-Peripheral model, research processes are described as a result of the interaction of the center and the periphery, with the unequal exchange between them, which, nevertheless, is systemically beneficial.

For example, the center of the innovative space attracts innovators from the periphery, thereby impoverishing it; at the same time, thanks to the concentration of innovators in the center, they have the opportunity to recombine their ideas and knowledge. The multiplier effect of such interaction is more significant, than the effect of a uniformly distributed innovative activity. The innovations, created at the center, subsequently extend to the periphery as finished products.

In reality, however, the situation is more complicated and only the two-part Center-Peripheral model is not enough to explain it. As a rule, a large part of a region or country generally lies outside the limits of the innovative space: innovations do not penetrate there or practically do not penetrate.

The addition of the third component - the semiperiphery (or province), where innovations penetrate from the center, supplanted by new ones, allows making more adequately innovative space description.

The formation of axes or corridors of development remains one of the research topics in the world science. The main methodological contribution to the research was made by French researchers F. Perroux [24] and P. Potier [25]. The latter in Pottier's research proposed the term "development axis". At the same time, there are not so many concrete proposals for allocation of such axes in the scientific literature.

At the intersection of the center-peripheral approach, the model of growth poles and development axes, it is possible to allocate a narrower, "translational" direction in the centerperipheral model. From its perspective, the focus of the study is on the links between the zones; the "center" and "periphery" will be allocated, based on the incoming and outgoing flows of matter, energy 
and information. Moreover, the development axis can be identified as a result of the zones interaction of the center-peripheral system [26].

As a result of the economic and innovative space polarization process, which is characteristic of many world countries, including Russia, there is a decrease in the share of the semi-peripheral part. This part is redeployed between the "central" (to a lesser extent) and "peripheral" (to a greater extent) zones. The authors consider that polarization is a system reaction to the weakening of the "center", the risks of its transformation into a "province".

Responding to this danger, the regional (economic, innovative) system is being rebuilt in such way, that it concentrates resources in the "center", increasing as much diversity as possible, combining possible combinations in the core of the system. Deficiencies of this process are weakening, social and cultural "emasculation" of the rest of the economic and socio-cultural space of the region [27].

These processes lead to the fact that the morphology of the regional central peripheral network is violated. Additionally, the situation may arise, where the average level of centers will be emasculated and "... the interaction of the key growth pole with the rest of the region" will be "... impossible without a network of growth poles of lower rank" [28, p.16].

As a result, there are practically no transitional (semi-peripheral) zones within the innovative space. Therefore, the diffusion of innovation and spillover effects are concentrated exclusively in the center zones. In this case, measures to expand the innovative space do not bring results: the concentration of innovative activity in individual nuclei remains.

This situation does not look alarming within the country, but at the regional level it poses a certain threat, since entire regions are unable to carry out modernization on the basis of new technological structure innovations. Their gap with innovative leaders is growing, which very soon begins to affect the efficiency of their economy. Following the peripheralization of the innovative space, the economic is peripheralized.

At the macro-regional level, the linear elements of the innovative space (axis of innovation development) are able to pass between large industrial areas that have nuclei-generators of knowledge and innovation.

\section{Results and Discussion}

In this research, we tested the hypothesis of the most significant manifestation of innovative spillover effects in those geographical areas, where the costeffectiveness of innovation is higher, than the national average, based on the empirical data of the Russian regions.

The latter is achieved thanks, firstly, to greater efficiency in the use of investment resources, and secondly, thanks to spillover effects associated with the support of the innovation process by actors of the informative and economic spaces.

The data for analysis were obtained from Federal State Statistics Service for 2014 - 2017 on the indicators of the technological innovation expenses and the volume of innovative goods, works and services in a regional context.

A significant issue is the investment lag in innovation and the release of innovative products. This hysteresis is associated with the speed of interaction between innovative and economic spaces. Authors believe that three years from the moment of investment in the production modernization and the release of finished investment products constitute the optimal lagging period.

A cartographic analysis of innovative activity in a regional context is used in this research. Its results are presented on the map (Fig. 2), which was compiled using the Vertical Mapper (module of MapInfo). Interpolation was carried out, using the Natural Neighbor method in a simple way, separately for each field of innovation in the city table.

An analysis of the territorial features of innovative efficiency made it possible to identify the "regions-centers" and "regions-peripheries" among the regional innovation systems of Russia, using the example of the Russian regions in 2017.

One of the main indicators of innovative activity, along with patent activity, is the volume of innovative goods i.e. quantities of produced innovative products. It is an official indicator used in Russian statistical data to assess the effectiveness of innovation results.

For analysis were used the absolute and relative indicators of the innovative products output: the volume of the innovative products production and the share in the total output.

The results of the analysis are presented in Figure 3. On the $X$ scale is the volume of innovative products, on the $\mathrm{Y}$ scale is the share of innovative products in the total cost of products. 


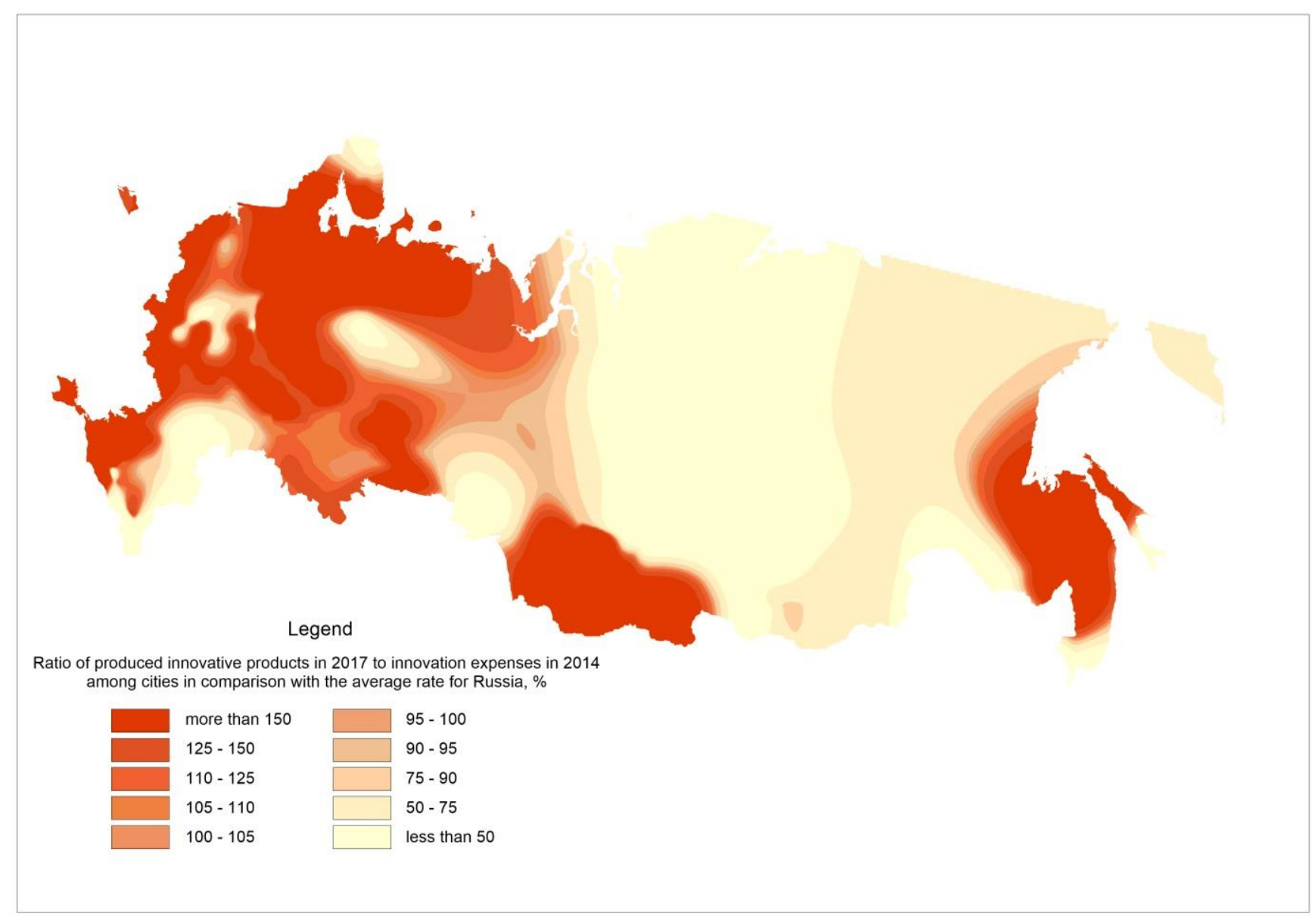

Fig. 2. The ratio of produced innovative products in 2017 to innovation expenses in 2014 in relation to average index throughout Russia

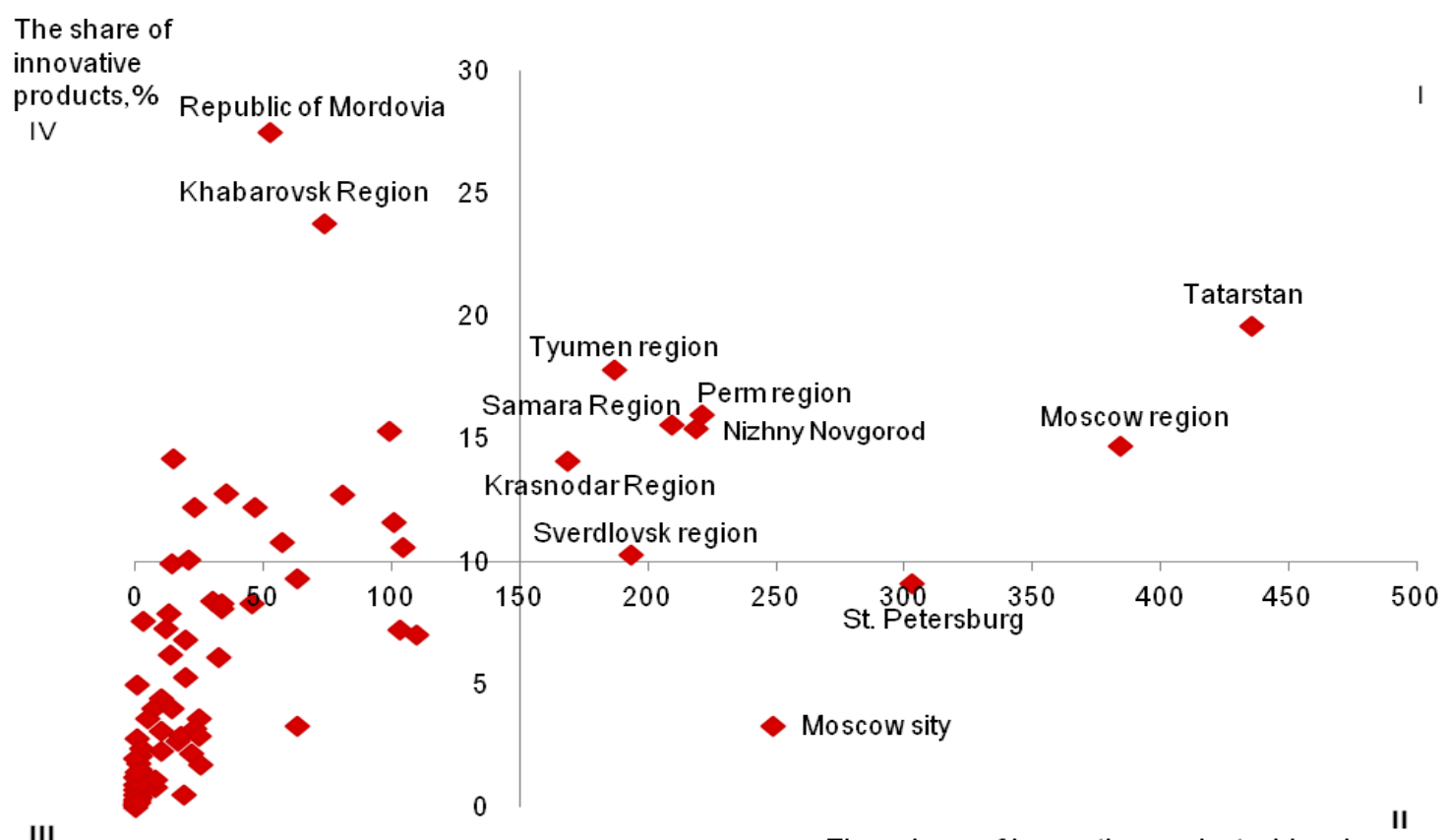

III

The volume of innovative products, bln rub.

Fig. 3. The spatial differentiation of innovative activity in the Russian regions, 2017 
The map on the Figure 2 clearly distinguishes three zones of advancing return on investment in innovation.

The first zone is the western zone. It is intermittent and has a complex shape. So, the Lower Volga region and the eastern part of the North Caucasus are less effective within it; Komi Republic; area to the northwest of Moscow (Novgorod region). At the same time, the north of the European part of Russia is characterized by a low density of innovation and economic activity. In fact, the South Ural - Moscow axis stands out, which includes a significant part of Russian millionaire cities, including Chelyabinsk, Yekaterinburg, Ufa, Perm, Kazan, Samara, Nizhny Novgorod. The second axis can be drawn from Moscow to the Black Sea coast (Rostov-on-Don, Krasnodar will be important nodes on the axis).

The second zone of increased efficiency is located in the Trans-Ural part of Russia - around Novosibirsk.

The third zone stands out in the Far East - around the Khabarovsk region.

The analysis of the Figure 3 shows that the «regions - centres» are located in the quadrant I. In this research the center includes regions with fairly high values of both of the above indicators. These are Tatarstan, Moscow, Nizhny Novgorod, Sverdlovsk, Samara, Tyumen regions, Perm and Krasnodar regions, i.e. mainly the regions of the Ural-Volga region.

In this research, regions with a relatively high share of innovative products, but relatively low gross values, are offered as innovative semiperiphery (quadrant IV). The Republic of Mordovia and the Khabarovsk Region (regions with the highest share of innovative products) stand out most. Moreover, the first refers to the Ural-Volga region, and the second is actually cut off from other zones of innovative activity.

The situation of two cities-regions of the Russian Federation (quadrant II) is very interesting: Moscow and St. Petersburg, in which the volume of innovative products is large, but its share in the total output is low. They can also be attributed to the semi - periphery.

Finally, the innovation periphery is the majority of the Russian regions with low values of both indicators in quadrant III.

In general, it can be noted that the types of regions, were identified in this research, correlate with the map of the innovation effectiveness. As expected, the analysis results allow to establish relations between the size of the regional economy (including due to the relatively high population density of Russian regions in quadrants I and II) and the volume of innovative products. In most of Asian Russia, on the contrary, it is lowered. Such a relation can be explained by the manifestation of regional spillover effects in European part of Russia due to the geographical proximity of innovative centres.

The knowledge spillover related processes are significant not only for high dense countries such European countries but also for the countries, were are great lags between they centres. Except the Russia they are Canada, Australia, Brazil. For those countries is vitally important to allocate the innovative carcass on the territory. Combining with the center-periphery approach that gives the picture of how the contours of the national innovative system should look alike.

The spatial differentiation of innovative activity by the regions, revealed by territorial and structure analysis, as we have shown in this paper, can clearly demonstrate the major parts of the innovative system, that should be connected by each other. This goal can be achieved by developing weak intermediate regions between the centres and also by creating the innovative infrastructure for all of the country. Those actions provide more active and efficient innovative spillover effect.

We believe that in future, polarization processes will help increased return areas on investment from innovation to snap-to the identified axes.

\section{Conclusion}

The variety of spillover effects that arise both between the allocated spaces and inside the innovative space itself, lead to the increase in concentration of innovations in individual centers. The allocated spaces determine the characteristics of each other.

The main contribution of the research comparison with the corresponding studies of spatial inequality is that the regions of the center and the periphery were identified in relation to the level of the innovative activity development throughout the Russian regions. Moreover, the manifestation of regional spillover effects was determined.

The centripetal process of the national innovative development is based on a high concentration of population, economic activity and R\&D in several large centers (Moscow, St. Petersburg, Novosibirsk, Kazan, and to a lesser extent in other millionaire cities). As a result, we can talk about the polarization of the innovative space.

The lack of second-order innovative centers does not allow innovations to spread from the cores, which leads to a lack of full-fledged semi-periphery, 
where the "worked out" innovations in the centers could shift. The gap between the center and the periphery leads even more to the flow of resources (including human capital, researchers) to the center.

It seems that, a monocentric space with the continuation of this trend will be formed with the main center in Moscow and several less significant cores gravitating to the coasts, as zones most integrated into the global economic space.

To prevent this trend, efforts should be made to form a sustainable innovation framework of the country and strengthen second-order innovation centers, which will increase the share of central regions.

Infrastructure investments are also needed to develop the transport network to reduce the economic distance, promote the growth of population mobility, eliminate the "gap" and ensure the "connectedness" of the innovative space to ensure an effective knowledge spillover between the regions of the Center and the Periphery.

The further research in the area of innovation space's structure has to be based on the more lower level, than regional level. The spatial inequality should be researched not only on the interregional, but also on intra regional level, where unfortunately is the lack of data.

The innovative process has multiple aspects, that may lead to intensify the polarization of innovation space or made it more homogeneous, create multipolar spatial structure. Complex consideration of this factors will increase our understanding of the way this space may be managed.

\section{Acknowledgements}

The research was supported by Russian Science Foundation (project No. 19-18-00199).

\section{References:}

[1] Hagerstrand T., Innovation Diffusion as a Spatial Process, Chicago. 1967

[2] Jaffe A., Trajtenberg M. and Henderson R., Geographic localization of knowledge spillovers as evidenced by patent citations, Quarterly Journal of Economics, 108, 1993, pp. 577-598.

[3] Head K., Ries J. and Swenson D., Agglomeration Benefits and Location Choice: Evidence from Japanese Manufacturing Investment in the United States, Journal of International Economics, 38, 1995, pp. 223247.

[4] Englmann F.C. and Walz U., Industrial Centers and Regional Growth in the Presence of Local
Inputs, Journal of Regional Science, 35, 1995, pp.3-27.

[5] Audretsch, D. B. and Feldman M. P., Knowledge Spillovers and the Geography of Innovation and Production, American Economic Review, 83, 1996, pp. 630-640.

[6] Sørensen N.K. and Cornett A. Systems of Innovation and Linkages in an Interregional Perspective: A Comparative Analysis of Northern Germany and Western Denmark, Industrial Clusters and Inter-Firm Networks, 2005, pp. 475-498.

[7] Song M., Van Der Bij H., Weggeman M., Determinants of the level of knowledge application: a knowledge-based and information-processing perspective, $J$ Prod Innov Manag, 22 (5), 2005, pp. 430-444.

[8] Capello R., Towards a new conceptualization of innovation in space: Territorial patterns of innovation, International Journal of Urban and Regional Research, 41(6), 2017, pp. 976-996.

[9] Prokop V., Stejskal J., Hajek P. The Influence of Financial Sourcing and Collaboration on Innovative Company Performance: A Comparison of Czech, Slovak, Estonian, Lithuanian, Romanian, Croatian, Slovenian, and Hungarian Case Studies. In: Stejskal J., Hajek P., Hudec O. (eds) Knowledge Spillovers in Regional Innovation Systems. Advances in Spatial Science. The Regional Science Series: Berlin : Springer, 2018, pp. 219-252.

[10] Esteban J. M. and Ray D., On the measurement of polarization, Econometrica, 62 (4), 1994, pp. 819-851.

[11] European Spatial Development Perspective. Towards Balanced and Sustainable Development of the Territory of the EU, European Commission, Luxembourg, 1999, 87 pp.

[12] Lukaze P., Economic Polarization across European Union Regions in the years 20072012 at NUTS 2 Level, Folia Oeconomica Stetin, 16, 2016, pp. 135-150.

[13] Zou C., Ou X. and Tan, J., Temporal and Spatial Characteristics and Early Warning Analysis of Economic Polarization Evolution: A Case Study of Jiangsu Province in China, Sustainability, 11, 2019, 1339.

[14] Tal M. S. and Maarten V.H., Neighbourhood change and spatial polarization: The roles of increasing inequality and divergent urban development, Cities, 82, 2018, pp.108-118.

[15] Alonso M. Structural Hegemony in Sub-Sahara Africa: Implications for Readjustment of 
Polarized Economic Regions, Ann. Assoc. Am. Geogr., 79, 2015, pp. 257-274.

[16] Firsova, A.A.; Makarova, E.L.; Tugusheva, R.R., Institutional Management Elaboration through Cognitive Modeling of the Balanced Sustainable Development of Regional Innovation Systems, J. Open Innov. Technol. Mark. Complex, 6, 2020, 32.

[17] Firsova A. and Chernyshova G. Modeling of Regional Innovation Spillover Effects Based on DEA Malmquist Index. In Proceedings of the Fourth Workshop on Computer Modelling in Decision Making (CMDM 2019), Atlantis Highlights in Computer Sciences, Saratov, Russia, 14-15 November 2019, pp. 103-107.

[18] Golichenko O., The Basic Factors of National Innovation System Development in Russia. Socio Economics and Technological Innovations Mechanism and Institutions, Delhi: Narosa Publishing House, 2014, pp. 38-52.

[19] Cherenkov V. I., Cherenkova N. I. and Maryanenko V. P., Semasiological approach to identifying the essence of the concept of "innovation" in economic science, Problems of modern Economics, 1, 2010, pp. 45-50.

[20] Minakir P. A. and Demyanenko A. N., Essays on spatial economics, Khabarovsk : Economic Research Institute Feb RAS, 2014.

[21] Baburin V. L. and Zemtsov S. P., Regionsinnovators and innovative periphery of Russia. Research of diffusion of innovations on the example of ICT products, Regional researches, 3(45), 2014, pp. 27-37.

[22] Blanutsa V. I., Spatial diffusion of innovations: sphere of uncertainty and network model, Regional studies, 3 (49), 2015, pp. 4-12.

[23] Ogurtsova E. V., Tugusheva R. R. and Firsova A. A., Innovation spillover effects of information and communications technology in higher education, Perspekt. Nauk. Obraz. Perspect. Sci. Educ. 42, 2019, pp. 409-421.

[24] Perroux F., Economic space: theory and applications, Quarterly Journal of Economics, 64, 1950, pp. 89-104.

[25] Pottier P., Axes de communication et developpement economique, Revue Economique, 14, 1963, pp. 58-132.

[26] Preobrazhenskiy Yu. V., Approaches to the identification of the Center and Periphery, $I z v$. Saratov Univ. (N. S.), Ser. Series: Earth Sciences, 16 (4), 2016, pp. 216-221.

[27] Preobrazhenskiy Yu. V., Formation of axes of development as a result of polarization of social and economic space. Socio-economic geography, Bulletin of the Association of
Russian social geographers, 7, 2018, pp. 196206.

[28] Ptichnikova G. A. and Antyufeev A.V., Dichotomy local-global and its role in spatial structuring of architectural space of the modern city, Sociology of the city, 1, 2015, pp. 5-19.

\section{Creative Commons Attribution License 4.0 (Attribution 4.0 International, CC BY 4.0)}

This article is published under the terms of the Creative Commons Attribution License 4.0 https://creativecommons.org/licenses/by/4.0/deed.en US 